\title{
Free-B-Ring flavonoids as potential lead compounds for colon cancer therapy
}

\author{
AHMED IBRAHIM $^{1}$, MOHAMED SOBEH $^{2}$, AYA ISMAIL $^{2}$, AHMED ALAA $^{2}$, \\ HUSSEIN SHEASHAA ${ }^{2}$, MOHAMED SOBH ${ }^{2}$ and FARID BADRIA ${ }^{3}$ \\ ${ }^{1}$ Department of Biochemistry, Faculty of Pharmacy; ${ }^{2}$ Medical Experimental Research Center, Faculty of Medicine; \\ ${ }^{3}$ Department of Pharmacognosy, Faculty of Pharmacy, Mansoura University, Mansoura 35516, Egypt
}

Received November 24, 2013; Accepted January 27, 2014

DOI: $10.3892 /$ mco. 2014.278

\begin{abstract}
Although flavonoids have been identified as a versatile source of anticancer agents, to the best of our knowledge, no study has yet investigated their anticolon cancer activity in depth. Therefore, the aim of this study was to investigate the association between the structural characteristics of flavonoids and their anticolon cancer activity in the Caco-2 human colon cancer cell line. Our findings demonstrated that the hydroxylation of $\mathrm{C} 5$ and $\mathrm{C} 7$ in ring A significantly enhanced the anticolon cancer activity of flavonoids over that of 5-fluorouracil, the classic reference cytotoxic agent. By contrast, the glycosylation or the presence of hydroxyl groups in ring B significantly decreased flavonoid anticancer activity. Collectively, these findings suggest a novel, rational design of flavonoid-related compounds that may improve the treatment of colorectal cancer.
\end{abstract}

\section{Introduction}

Colorectal cancer (CRC) is the third most common type of cancer worldwide (1). The treatment options for CRC are currently limited, with poor efficacy and marked variation in the therapeutic outcomes among patients. In the majority of cases, surgical resection remains the only curative treatment option; however, it involves costly and invasive procedures with considerable limitations. Therefore, the design of non-invasive and effective therapies is of prime importance.

Over the last decade, extensive research has focused on multiple synthetic chemotherapeutic agents that are non-invasive, but display low selectivity and severe adverse effects (2).

Correspondence to: Professor Farid Badria, Department of Pharmacognosy, Faculty of Pharmacy, Mansoura University, Building B, El-Gomhouria, Mansoura 35516, Egypt

E-mail: faridbadria@gmail.com

Dr Ahmed Ibrahim, Department of Biochemistry, Faculty of Pharmacy, Mansoura University, Mansoura 35516, Egypt

E-mail: ahmedsalahibrahim@yahoo.com

Key words: colorectal cancer, flavonoids, free-B-Ring flavonoids
The cornerstone of adjuvant and palliative chemotherapy for CRC is currently 5-fluorouracil (5-FU) (3). However, 5-FU has been associated with several side effects, including myelotoxicity (4), gastrointestinal disturbances (5), cardiotoxicity (6) and hepatotoxicity (7). Those limitations prompted investigators to design a more effective and safe drug, which may enhance the therapeutic benefits for CRC patients.

Epidemiological studies have consistently documented high incidence rates of CRC in Australia, New Zealand, Europe and North America. By contrast, low incidence rates of CRC have been reported in Africa and South-Central Asia, where the intake of fruits and vegetables is high (8). These epidemiological findings suggest the possibility of a causal association between habitual dietary intake and the incidence of CRC. Furthermore, these observations were substantiated by the conclusion of the World Cancer Research Fund, which reported an inverse association between the dietary intake of fruits or vegetables, flavonoid-rich diets and the incidence of CRC (9).

The basic chemical structure of flavonoids is based on a C6-C3-C6 system with a chromane ring bearing a second aromatic B ring in position 2, 3 or 4. Flavonoids are polyphenolic compounds present in a free state or as glycosides, usually $\mathrm{O}$-glycosides, with the sugar moiety generally bound to the aglycone hydroxyl $(\mathrm{OH})$ group at C-7 or, occasionally, C-3. The typical sugar moieties include D-glucose and L-rhamnose. Over 6,000 plant flavonoids have been described and classified into at least 10 chemical groups according to structural patterns (10). However, laboratory and epidemiological studies have focused mainly on bioflavonoids, including rutin, quercetin, chrysin, hesperetin and hesperidin, grouped under the following three flavonoid subgroups: flavonols, flavones and flavanones (Fig. 1). Flavonols, such as quercetin and its glycoside, rutin, are the most abundant flavonoids in foods and are found in leafy vegetables, apples, onions and berries. Flavones, such as chrysin, are found in honey and propolis and in low concentrations in fruits, vegetables and certain beverages. Flavanones, such as hesperetin and its glycoside, hesperidin, also known as citrus flavonoids, are found in citrus fruits and their juices (11).

Although a broad spectrum of biological activities has been identified for these flavonoids, no study has yet investigated their anticolon cancer activity in depth. The proposed 
<smiles>O=c1cc(-c2ccccc2)oc2ccccc12</smiles>

Flavone<smiles>O=c1c(O)c(-c2ccccc2)oc2ccccc12</smiles>

3-Hydroxyflavone<smiles>COc1ccc([C@H]2CC(=O)c3c(O)cc(O)cc3O2)cc1O</smiles>

Hesperetin<smiles>O=c1cc(-c2ccccc2)oc2cc(O)cc(O)c12</smiles>

Chrysin<smiles></smiles>

Quercetin

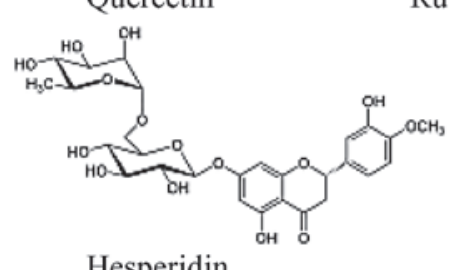

Hesperidin

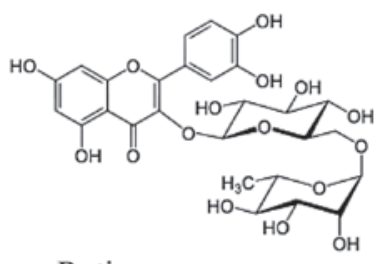

Rutin

Figure 1. Structural characteristics of the naturally-derived flavonoids flavone, chrysin, 3-hydroxyflavone, quercetin, rutin, hesperetin and hesperidin.

protective role of flavonoids against tumor development may prevail in the intestinal tract due to direct exposure to intestinal epithelia. Therefore, this study aimed to investigate the potential anticolon cancer activity of these structurally diverse flavonoids in comparison to that of 5-FU and delineate the association between structural characteristics and anticolon cancer activity. Such findings may simplify drug design to allow safer and more effective anticolon cancer pharmaceuticals to be synthesized.

\section{Materials and methods}

Materials and reagents. Dulbecco's modified Eagle's medium (DMEM) was obtained from Gibco-BRL (Invitrogen Life Technologies Inc., Grand Island, NY, USA). Non-essential amino acids and fetal calf serum (FCS) were purchased from Hyclone (Logan, UT, USA). Penicillin and streptomycin were purchased from Amresco (Solon, OH, USA). The flavonoids were previously isolated at the Department of Pharmacognosy, Faculty of Pharmacy, Mansoura University (Mansoura, Egypt) and identified by ultraviolet, infrared, mass and nuclear magnetic resonance spectroscopy. The purity of flavonoids was $>99 \%$, assessed by high-performance liquid chromatography. Plates of 96 wells were purchased from Corning Inc. (Cambridge, MA, USA).

Cell culture. The Caco-2 human colon adenocarcinoma cell line was purchased from American Type Culture Collection (HTB-37; Rockville, MD, USA). The Caco-2 cells were cultured in DMEM containing D-glucose $(4.5 \mathrm{~g} / \mathrm{l})$, $\mathrm{NaHCO}_{3}(3.7 \mathrm{~g} / \mathrm{l})$ and supplemented with $10 \% \mathrm{FCS}$, penicillin (100 U/ml) and streptomycin $(100 \mu \mathrm{g} / \mathrm{ml})$, in an atmosphere of $5 \% \mathrm{CO}_{2}$ and $95 \%$ relative humidity at $37^{\circ} \mathrm{C}$. All the cells used in this study were between passages 50 and 62 .

Drug treatment. The concentration of the investigated flavonoids was 50-250 $\mu \mathrm{M}$. The flavonoids were dissolved in
100\% dimethylsulfoxide (DMSO; Sigma, St. Louis, MO, USA) and diluted to their final concentrations in serum-free media. In all the experiments, the control cells were incubated with DMSO alone. The final concentration of DMSO was maintained at $0.2 \% \mathrm{w} / \mathrm{v}$. The cells were incubated with flavonoids or 5 -FU for 24,48 and $72 \mathrm{~h}$.

Cytotoxicity assay. Cytotoxicity was assessed with the MTT assay, according to the manufacturer's recommendations (Roche Diagnostics GmbH, Mannheim, Germany). The experiments were repeated 3 times and data are expressed as means \pm standard deviation (SD). This assay relies on the ability of metabolically active viable cells to reduce a yellow tetrazolium salt (MTT; Sigma) to a purple formazan product. This reaction occurs when mitochondrial reductase enzymes are active. The cells were grown in 96-well plates (1x10 $/ 200 \mu \mathrm{l} /$ well). Following incubation with the reagents, the medium was removed and the cells were treated with $20 \mu \mathrm{l}$ of MTT $(5 \mathrm{mg} / \mathrm{ml})$ for $3 \mathrm{~h}$ at $37^{\circ} \mathrm{C}$. Subsequently, $100 \mu \mathrm{l}$ DMSO was added to each well. The solubilized formazan product was spectrophotometrically quantified using a PowerWave XS microplate reader (BioTek, Winooski, VT, USA) at $540 \mathrm{~nm}$.

Statistical analysis. Data are presented as means \pm SD. Statistical comparisons between groups were performed by one-way analysis of variance (ANOVA) followed by post hoc Tukey's test (Statistica; StatSoft Inc., Tulsa, OK, USA). P<0.05 was considered to indicate a statistically significant difference.

\section{Results}

Dose-viability response of 5-FU. The anticolon cancer activities of the selected flavonoids were evaluated in a cell-based assay using Caco-2 cells and compared to that of 5-FU, a drug extensively used in adjuvant and palliative chemotherapy for $\mathrm{CRC}$. The dose response and time course cytotoxicity of the 

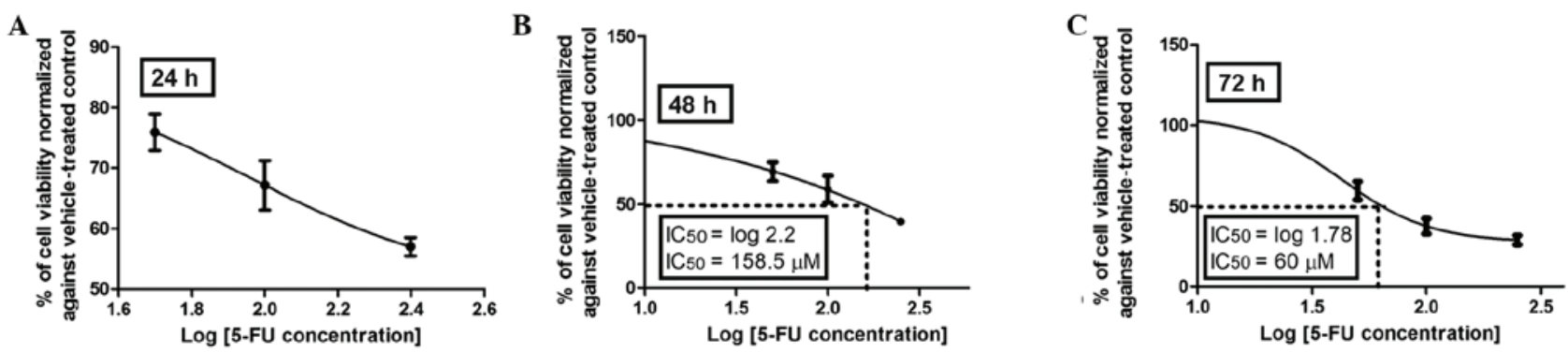

Figure 2. $\mathrm{IC}_{50}$ of 5-FU following incubation for (A) 24, (B) 48 and (C) $72 \mathrm{~h}$ at different concentrations (50, 100 and $250 \mu \mathrm{M}$ ) (counted as a percentage of untreated control, $0 \mu \mathrm{M}$ ). Data shown are the means $\pm \mathrm{SD}$ of 3 experiments. 5-FU, 5-fluorouracil; $\mathrm{IC}_{50}, 50 \%$ inhibitory concentration.

A

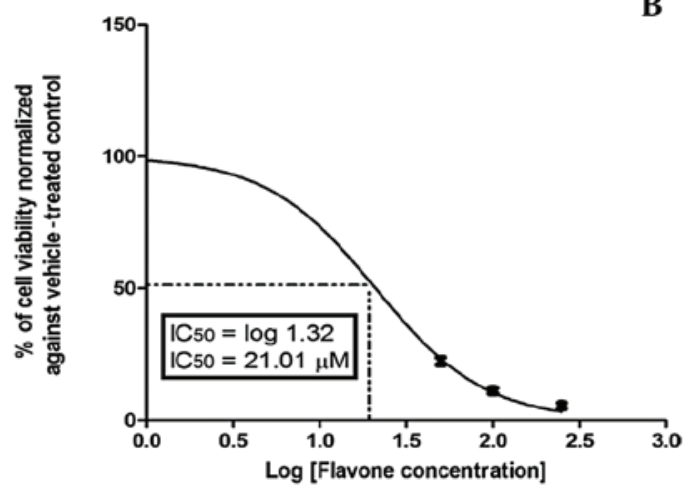

B

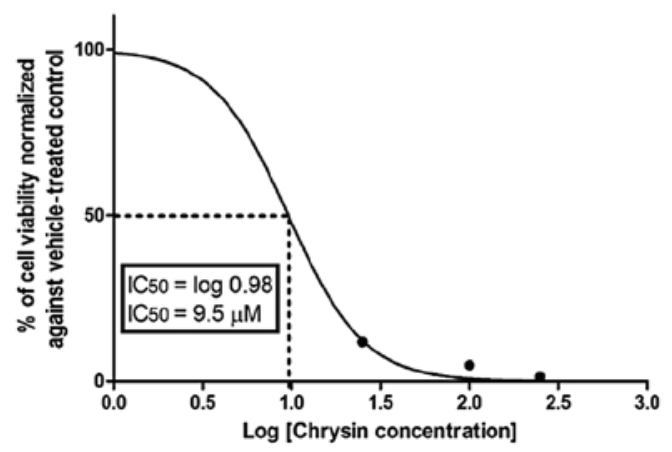

Figure 3. $\mathrm{IC}_{50}$ of flavone flavonoids. $\mathrm{IC}_{50}$ of (A) flavone and (B) chrysin following incubation for $72 \mathrm{~h}$ at different concentrations $(50,100$ and $250 \mu \mathrm{M})($ counted as a percentage of untreated control, $0 \mu \mathrm{M}$ ). Data shown are the means $\pm \mathrm{SD}$ of 3 experiments. $\mathrm{IC}_{50}, 50 \%$ inhibitory concentration.
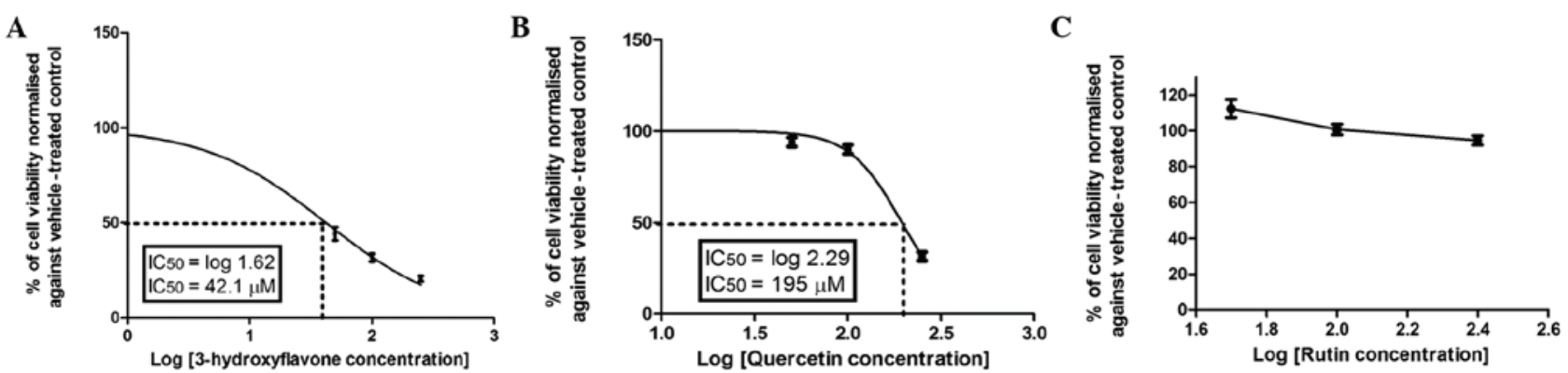

Figure 4. $\mathrm{IC}_{50}$ of flavonol flavonoids. $\mathrm{IC}_{50}$ of (A) 3-hydroxyflavone, (B) quercetin and (C) rutin following incubation for $72 \mathrm{~h}$ at different concentrations (50, 100 and $250 \mu \mathrm{M}$ ) (counted as a percentage of untreated control, $0 \mu \mathrm{M}$ ). Data shown are the means $\pm \mathrm{SD}$ of 3 experiments. $\mathrm{IC}_{50}, 50 \%$ inhibitory concentration.

standard agent, 5-FU, were initially evaluated with the MTT assay. As shown in Fig. 2A-C, the dose-response effect of 5-FU was more evident after $72 \mathrm{~h}$ of incubation with an inhibitory concentration $\left(\mathrm{IC}_{50}\right)$ of $60 \mu \mathrm{M}$ compared to that at $48 \mathrm{~h}$ of incubation with an $\mathrm{IC}_{50}$ of $158.5 \mu \mathrm{M}$, whereas at $24 \mathrm{~h}$ an $\mathrm{IC}_{50}$ was not reached with 5-FU at any of the concentrations investigated $(50-250 \mu \mathrm{M})$. Therefore, $72 \mathrm{~h}$ was selected as the incubation period to assess the dose-viability response of the investigated flavonoids (Figs. 3-6).

Anticancer potency of flavonoids. Among the investigated flavonoids in this cell-based assay, flavone, chrysin (Fig. 3A and B) and 3-hydroxyflavonol (Fig. 4A) exhibited the highest anticancer potencies, which were superior or comparable to that of 5-FU. By contrast, quercetin was not active, even at concentrations up to $100 \mu \mathrm{M}$ (Fig. 4B). Notably, hesperetin (Fig. 5A) exhibited a moderate $\mathrm{IC}_{50}$ that was significantly lower compared to that of quercetin, but higher compared to those of flavone and chrysin.

Cytotoxicity of flavone. The dose-viability response (counted as percentage of control, $0 \mu \mathrm{M}$ ) in Caco- 2 cells during $72 \mathrm{~h}$ of incubation with different concentrations of flavone, the form commonly found in fresh plants, which is then converted to different flavonoid derivatives by benzopyrene hydroxylases, is shown in Fig. 1. Flavone exerted a strong cytotoxic effect against Caco-2 cells in a dose-dependent manner, with an $\mathrm{IC}_{50}$ of $21.01 \pm 1.3 \mu \mathrm{M}$. 
A

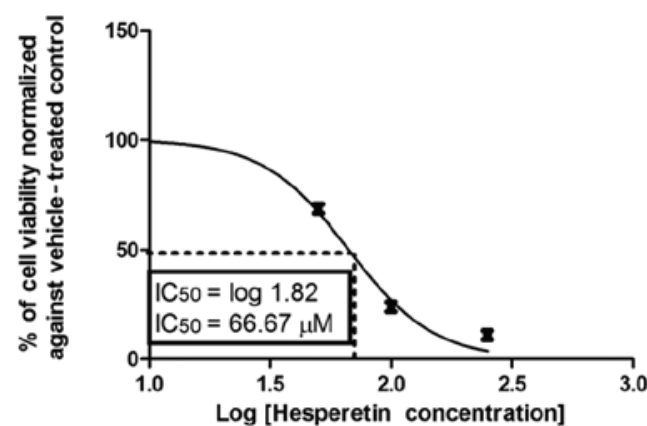

B

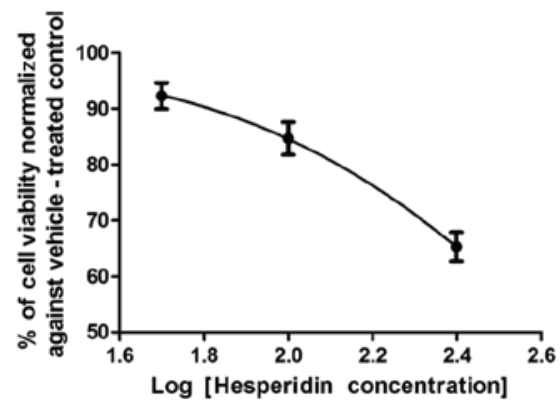

Figure 5. $\mathrm{IC}_{50}$ of flavanone flavonoids. $\mathrm{IC}_{50}$ of (A) hesperetin and (B) hesperidin following incubation for $72 \mathrm{~h}$ at different concentrations $(50,100$, and $250 \mu \mathrm{M})$ (counted as a percentage of untreated control, $0 \mu \mathrm{M}$ ). Data shown are the means $\pm \mathrm{SD}$ of 3 experiments. $\mathrm{IC}_{50}, 50 \%$ inhibitory concentration.

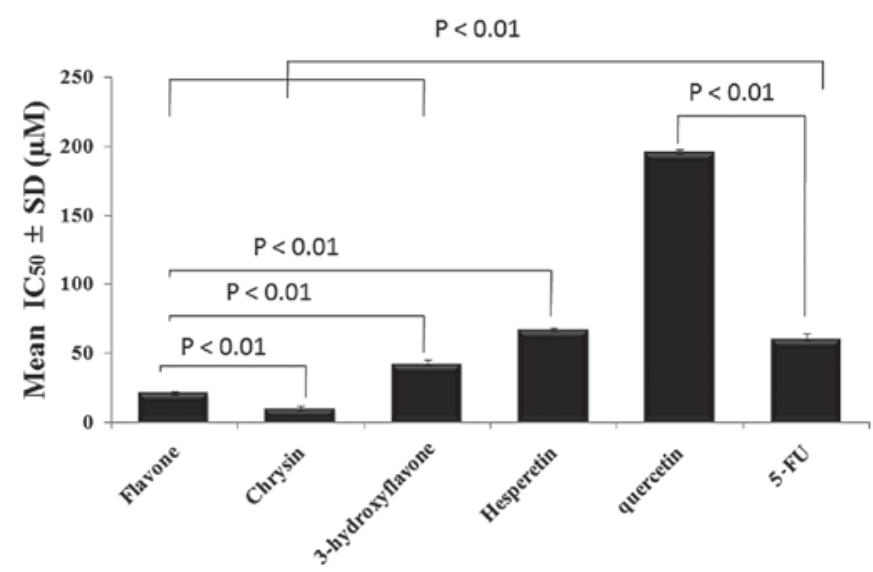

Figure 6. Statistical differences in anticolon cancer effect at $\mathrm{IC}_{50}$ for each flavonoid after $72 \mathrm{~h}$ of incubation. The means were significantly different across the samples. Data shown are the means \pm SD of 3 experiments.

Association between structural characteristics of flavonoids and anticancer activity. In light of the anticancer effects of flavone, we sought to determine whether the addition of functional groups modifies its anticancer activity. The addition of $\mathrm{OH}$ groups in ring A significantly enhanced the anticolon cancer activity of flavone, as shown in Fig. 3B for chrysin. Chrysin, which has $2 \mathrm{OH}$ groups in ring $\mathrm{A}$, caused $50 \%$ inhibition of colon cancer cell proliferation at a concentration of $9.5 \pm 2.2 \mu \mathrm{M}$, which was significantly $(\mathrm{P}<0.01)$ lower compared to that of flavone. However, introducing a $\mathrm{OH}$ group in ring $\mathrm{C}$ caused a significant decrease in the anticancer activity of flavone, as shown in Fig. 4A for 3-hydroxyflavone. Furthermore, the addition of a $\mathrm{OH}$ group in ring $\mathrm{B}$ resulted in a marked decrease in the anticancer activity of flavonoids, as shown in Figs. 4B and 5A for quercetin and hesperetin, respectively. Hesperetin, which has a $\mathrm{OH}$ group in ring $\mathrm{B}$, caused a $50 \%$ reduction in the viability of Caco-2 cells after $72 \mathrm{~h}$ of incubation at a concentration of $66.67 \pm 1.5 \mu \mathrm{M}$ (Fig. 5A). The addition of the second $\mathrm{OH}$ group in ring $\mathrm{B}$ resulted in a significant decrease in anticolon cancer activity, as illustrated by quercetin, which caused a $50 \%$ inhibition of cell viability after $72 \mathrm{~h}$ of incubation at a concentration of $195 \pm 2.5 \mu \mathrm{M}$ (Fig. 4B). Furthermore, the addition of sugar moieties at position 3 exerted a greater effect on the anticolon cancer activity of quercetin. This is clearly manifested in rutin, in which the cytotoxic activity was significantly diminished over the applied concentration range (Fig. 4C). The addition of sugar moieties at position 7 in ring $\mathrm{A}$ distinctly reduced the anticolon cancer effect of hesperitin over the concentration range, as manifested in hesperidin (Fig. 5B).

One-way ANOVA was used to evaluate the statistical significance of the difference in the anticolon cancer effect at $\mathrm{IC}_{50}$ for each flavonoid after an incubation period of $72 \mathrm{~h}$ and the means were found to be significantly different across the samples (Fig. 6).

\section{Discussion}

Effective therapies for colon cancer, which is considered to be a disease of the civilization, have long been the focus of investigation. Despite the clinical success of several newly developed anticolon cancer agents, there are certain limitations, such as high peripheral neurotoxicity, complicated synthesis procedures and drug resistance conferred by multidrug resistance transporters. Therefore, there has been an increasing interest in identifying novel anticolon cancer agents with alternative modes of action and improved pharmacological profiles, particularly reduced toxicity. The re-emphasis on natural products in drug discovery was the subject of recent cancer research and development and was shown to be a valuable, effective and inexpensive approach $(12,13)$. In the present study, the use of naturally-derived Free-B-Ring flavonoids as potential anticolon cancer agents was investigated.

Free-B-Ring flavonoids are benzo- $\gamma$-pyrone derivatives found in a number of medicinal plant species and possess a plethora of biological and pharmacological properties. Over several years, the development and use of these flavonoids and their derivatives for the prevention and treatment of cancer has been a focus of investigation. Chrysin, the most abundant Free-B-Ring flavonoid in honey, was found to potentiate the antiproliferative effect of various chemotherapeutic agents (14). Furthermore, chrysin was found to be capable of inhibiting cell proliferation and inducing apoptosis in human cervical carcinoma (15), leukemia (16), esophageal squamous cell carcinoma (17), malignant glioma, breast carcinoma (18) and prostate cancer cell lines (19). To extend our knowledge of the antineoplastic role of chrysin, the present study demonstrated the ability of chrysin to induce colon cancer cell death more efficiently compared to 5-FU. 
Additionally, flavones and 3-hydroxyflavone are among the Free-B-Ring flavonoid derivatives that were investigated in this study and exhibited more efficient anticolon cancer activities compared to that of 5-FU. Given these properties, Free-B-Ring flavonoids may be promising anticolon cancer agents, a hypothesis originating partly from a previous study demonstrating that baicalein (5,6,7-trihydroxyflavone) exerted an antiproliferative effect on Caco-2 cells (20). That initial study was further supported by the observation that flavone increased early and late apoptosis parameters in Caco-2 cells (21). Additionally, those findings were reinforced by more recent studies, demonstrating that 5,7-dihydroxy-3,6,8-trimethoxy flavone displayed a potent activity against the more differentiated carcinomas of the colon compared to its flavonol isomer, 5-hydroxy-6,7,8-trimethoxy-3-flavonol (22). Taken together, those findings have formed the concept of Free-B-Ring flavonoids as potential anticolon cancer agents and several mechanisms have been proposed regarding their anticancer activity. One such mechanism refers to the ability of these agents to inhibit DNA topoisomerase II (23), whereas another refers to their ability to produce free radicals and, consequently, cleave DNA (24).

In concordance with previous findings, the potent cytotoxicity of three Free-B-Ring flavonoids against Caco-2 cells was observed in our study. However, to the best of our knowledge, our study is the first to report that, although the basic chemical structures of various flavonoids are similar, the specific functional groups attached at specific positions, particularly the $\mathrm{OH}$ group, may confer significantly different bioactivities to the resulting compounds. Chrysin, which has $2 \mathrm{OH}$ groups in the A ring, was the most active compound to arrest Caco-2 cell survival followed by flavone, 3-hydroxyflavone, hesperitin, quercetin, hesperidin and finally rutin. In addition, we demonstrated the causal association between the structural characteristics and the activity of these flavonoids, as the acquisition of the $\mathrm{OH}$ group in the $\mathrm{B}$ ring significantly decreased their anticancer activity; in a similar manner, glycosylation was also associated with a marked decrease in anticancer activity.

In conclusion, with the ongoing demand for novel drug-like lead compounds against CRC, the significant anticancer activity of Free-B-Ring flavonoids compared to standard therapy renders them potential leads to future anticolon cancer agents.

\section{References}

1. Greenlee RT, Hill-Harmon MB, Murray T and Thun M: Cancer statistics, 2001. CA Cancer J Clin 51: 15-36, 2001.

2. Dhorajiya BD, Ibrahim AS, Badria FA and Dholakiya BZ: Design and synthesis of novel nucleobase-based barbiturate derivatives as potential anticancer agents. Med Chem Res August, 2013, 1-doi: 10.1007/s00044-013-0683-4.

3. Quasar Collaborative Group, Gray R, Barnwell J, McConkey C, Hills RK, Williams NS and Kerr DJ: Adjuvant chemotherapy versus observation in patients with colorectal cancer: a randomised study. Lancet 370: 2020-2029, 2007.
4. Choi EH, Ok HE, Yoon Y, Magnuson BA, Kim MK and Chun HS: Protective effect of anthocyanin-rich extract from bilberry (Vaccinium myrtillus L.) against myelotoxicity induced by 5-fluorouracil. Biofactors 29: 55-65, 2007.

5. Meta-Analysis Group In Cancer: Toxicity of fluorouracil in patients with advanced colorectal cancer: effect of administration schedule and prognostic factors. Meta-Analysis Group In Cancer. J Clin Oncol 16: 3537-3541, 1998.

6. Jensen SA, Hasbak P, Mortensen J and Sørensen JB: Fluorouracil induces myocardial ischemia with increases of plasma brain natriuretic peptide and lactic acid but without dysfunction of left ventricle. J Clin Oncol 28: 5280-5286, 2010.

7. Choti MA: Chemotherapy-associated hepatotoxicity: do we need to be concerned? Ann Surg Oncol 16: 2391-2394, 2009.

8. Haggar FA and Boushey RP: Colorectal cancer epidemiology: incidence, mortality, survival, and risk factors. Clin Colon Rectal Surg 22: 191-197, 2009.

9. World Cancer Research Fund/American Institute for Cancer Research: Food, Nutrition and the Prevention of Cancer: a Global Perspective. American Institute for Cancer Research, Washington, DC: AICR, pp. 134-136, 1997.

10. Heim KE, Tagliaferro AR and Bobilya DJ: Flavonoid antioxidants: chemistry, metabolism and structure-activity relationships. J Nutr Biochem 13: 572-584, 2002.

11. Yao LH, Jiang YM, Shi J, Tomas-Barberan FA, Datta N, Singanusong R and Chen SS: Flavonoids in food and their health benefits. Plant Foods Hum Nutr 59: 113-122, 2004.

12. Koehn FE (ed): Natural products and cancer drug discovery. Humana Press, New York, NY, 2013.

13. BadriaFA and Ibrahim AS: Evaluation of natural anthracene-derived compounds as antimitotic agents. Drug Discov Ther 7: 84-89, 2013.

14. Gao AM, Ke ZP, Shi F and Chen H: Chrysin enhances sensitivity of BEL-7402/ADM cells to doxorubicin by suppressing PI3K/Akt/Nrf2 and ERK/Nrf2 pathway. Chem Biol Interact 206: 100-108, 2013.

15. Zhang T, Chen X, Qu L, Wu J, Cui R and Zhao Y: Chrysin and its phosphate ester inhibit cell proliferation and induce apoptosis in HeLa cells. Bioorg Med Chem 12: 6097-6105, 2004.

16. Khoo BY, Chua SL and Balaram P: Apoptotic effects of chrysin in human cancer cell lines. Int J Mol Sci 11: 2188-2199, 2010

17. Zhang Q, Zhao XH and Wang ZJ: Cytotoxicity of flavones and flavonols to a human esophageal squamous cell carcinoma cell line (KYSE-510) by induction of G2/M arrest and apoptosis. Toxicol In Vitro 23: 797-807, 2009.

18. Lirdprapamongkol K, Sakurai H, Abdelhamed S, Yokoyama S, Maruyama T, Athikomkulchai S, Viriyaroj A, Awale S, Yagita H, Ruchirawat S, Svasti J and Saiki I: A flavonoid chrysin suppresses hypoxic survival and metastatic growth of mouse breast cancer cells. Oncol Rep 30: 2357-2364, 2013.

19. Samarghandian S, Afshari JT and Davoodi S: Chrysin reduces proliferation and induces apoptosis in the human prostate cancer cell line PC-3. Clinics (Sao Paulo) 66: 1073-1079, 2011.

20. Kuntz S, Wenzel U and Daniel H: Comparative analysis of the effects of flavonoids on proliferation, cytotoxicity, and apoptosis in human colon cancer cell lines. Eur J Nutr 38: 133-142, 1999.

21. Wenzel U and Daniel H: Early and late apoptosis events in human transformed and non-transformed colonocytes are independent on intracellular acidification. Cell Physiol Biochem 14: 65-76, 2004.

22. Thomas CM, Wood RC III, Wyatt JE, Pendleton MH, Torrenegra RD, Rodriguez OE, Harirforoosh S, Ballester M, Lightner J, Krishnan K and Ramsauer VP: Anti-neoplastic activity of two flavone isomers derived from Gnaphalium elegans and Achyrocline bogotensis. PLoS One 7: e39806, 2012.

23. Austin CA,Patel S, Ono K, Nakane H and Fisher LM: Site-specific DNA cleavage by mammalian DNA topoisomerase II induced by novel flavone and catechin derivatives. Biochem J 282: 883-889, 1992.

24. Marozienė A, Nemeikaitè-Čènienè A, Vidžiūnaitė R and Čenas N: Correlation between mammalian cell cytotoxicity of flavonoids and the redox potential of phenoxyl radical/phenol couple. Acta Biochim Pol 59: 299-305, 2012. 